CHRISTINE JORM S)

Reconstructing

Medical Practice

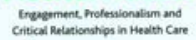

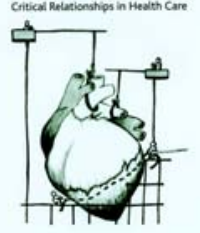

\title{
A clarion call for change
}

Reconstructing medical practice: engagement, professionalism and critical relationships in health care. Christine Jorm. Farnham, Surrey, UK: Gower Publishing Limited, 2012 (244 pp, \$123.95). ISBN 9781409429753.

PROPOSALS FOR CHANGE, states Machiavelli, with whom the book opens, are met with retaliation from those "who do well out of the old order". Jorm's book regards "the old order" as "senior consultants doing it this way for twenty or thirty or forty years". But another, more recent, order is also under fire: the increasing bureaucratic regulation of medical practice enacted by "primitive and poorly resourced" management.

The author is an associate professor of medical education at the University of Sydney, New South Wales, and is the coordinator of the Professional and Personal Development Theme of the university's medical program.

The book's main concern is doctors' disengagement from the system of health care, and the resulting threat to quality of care and patient safety. Jorm's findings are based on 41 interviews, two focus group discussions and 85 survey responses. Rich with interview quotes and survey analyses, the book takes us on a painstaking journey through the doctors' deep commitment to medicine, their personal sacrifices for their patients, their sense of loss and professional disintegration, and their disappointment in the face of political and bureaucratic expediency, and the increasing intrusiveness of micromanagerial and administrative regulation.

Others have decried the state of our health system (I'm thinking of Mohamed Khadra's Terminal decline), but few have taken medicine's own pulse to test its capacity and preparedness for health reform. Jorm's diagnosis reveals doctors' strengths (they're smart, committed and capable of handling uncertainty, and are good risk-takers) as well as their weaknesses (they have trouble acknowledging errors, they avoid confronting or reporting colleagues, and they disengage from the broader system). She describes the doctors in her study as being both entwined in dense collegial networks, thriving on the constant negotiation of medical uncertainty, but also isolated in their practices and specialties, having lost the stability of relationships that used to define their hospital work and patient care. For health care managers, however, "the messages are more confronting". Like Khadra, Jorm has little patience with underqualified managers, inept bureaucrats and opportunistic politicians.

What does she recommend to resolve the stalemate? That doctors need to become more active agents of change. That their attitude towards professionalism needs to expand to take on managerial and organisational responsibilities. That doctors need to take charge, but to do so they need to "learn to see and influence the system".

This will become possible once they have appropriate data and measurements; once they take on their own emotional responses, and learn how to become leaders "in introducing a new order of things". Eschewing quality and safety's reverence for aviation and transportation, the book ends on a military flourish and raises a flag for the renewed appreciation of the role of command and control, and of determination. The task for doctors is to secure "an expanded sense of place and relationships" such that they gain "more control over the organization of their work". Central to this task is "rebuilding of the relationship between the doctor and the hospital".

Overall, the book offers a probing insight into contemporary doctoring. It is a clarion call to practising doctors: if you care for your patients, you can't turn away from the system of care. To understand and act on the system, open yourselves up to the social disciplines, where strategies have been conceptualised on how to change an order that disenfranchises doctors and disadvantages patients. Not since Miles Little's Humane medicine has such an impassioned plea been put to doctors about how to reinvent their work and reinvest it with meaning and purpose.

Rick A M ledema Director Centre for Health Communication University of Technology Sydney,
Sydney, NSW doi: 10.5694/mjal2.10976

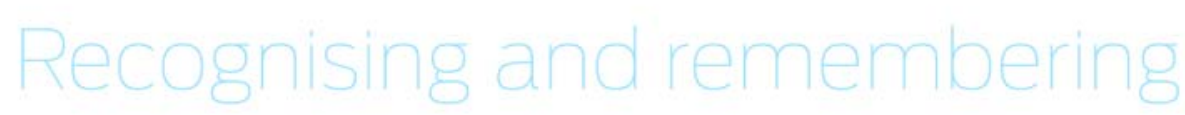

The MJA would like to encourage its readers to submit obituaries of doctors who have died within the past 6 months so that we can acknowledge their contribution to the medical community. The obituaries should consist of approximately 350 words and include biographical details such as last position held, place and date of birth, place of qualification and date (if possible), postgraduate qualifications and personal interests. An electronic photograph should accompany the obituary, preferably 300 dpi, jpeg or tiff file. The obituary may be published in print and online, or online only. The article may be truncated in the print version. 